\title{
AESTHETIC COGNITION IN ARCHITECTURAL EDUCATION: A METHODOLOGICAL APPROACH TO DEVELOP LEARNING PROCESS IN DESIGN STUDIOS
}

Dr. Rokhsaneh Rahbarianyazd, Faculty of Architecture, Department of Architecture, Alanya HEP University, Turkey, E-mail: rokhsaneh.rahbarianyazd@gmail.com

Dr. Hourakhsh Ahmad Nia, Faculty of Architecture, Department of Architecture, Alanya HEP University, Turkey, E-mail: hourakhsh_ahmadnia@yahoo.com

ARTICLE INFO

Original Research

Received: August, 18.2019.

Revised: September, 15.2019.

Accepted: October, 16.2019.

doi: 10.5937/IJCRSEE1903061R

UDK

378.6:72(560)

$378.147:: 111.852(560)$

Keywords:

Aesthetic Cognition;

Architectural Education;

Design studio;

Learning Process.

\section{A B S T R A C T}

Aesthetics and the design studio have been widely regarded as germane to architecture education and architectural design education respectively. Despite this obvious importance and relationship, very scant studies have been done on how aesthetics as a concept, has been thought in architectural schools especially with regard to the pedagogue of acquiring aesthetic knowledge as perceived by instructors and students in the Design Studio. Moreover, despite its centrality in architectural studies, there is a current gap in literature pertaining to aesthetics and the steps to teaching it in architectural design studios. This paper presents a discussion on the aesthetics and the process of teaching it in design studio using a qualitative grounded theory approach. In view of the paucity of work on the teaching pedagogue in architectural design studios, this study aim at shedding light on how students and studio instructors perceive the extant state of the methods of teaching aesthetics and identify the aesthetics of architecture. In this regard, the study by hypothesizing the design studios as the core contributor in architectural design developed the contributing elements in aesthetic education of architecture.

(c) 2019 IJCRSEE. All rights reserved.

\section{INTRODUCTION}

The design studio is central to design curriculum (Demirbas and Demirkan, 2003). Indeed, Schön (1985) puts it that it is the fulcrum of architectural education. Design studio based techniques are generally accepted (Vyas et al., 2013). Significant in these techniques are the relationships (social and interpersonal) that develop amongst the students and between the student and tutor. This sort of teamwork (Vyas et al., 2013) is important to the decisions made in the design studio. Yang (2010) pointed out that much work has been done in this regard. Thus, on this note, Demirkan and Afacan (2012)

\footnotetext{
Corresponding Author

Dr. Rokhsaneh Rahbarianyazd, Faculty of

Architecture, Department of Architecture, Alanya

HEP University, Turkey,

E-mail: rokhsaneh.rahbarianyazd@gmail.com
}

\section{c)}

This work is licensed under a Creative Commons Attribution - NonCommercial - NoDerivs 4.0. The article is published with Open Access at www.ijcrsee.com pointed out that it is imperative for students of architecture to create their own set of design thinking (Dorst 2011) and creative techniques which in the long run will increasingly benefit the general populace (Stošić and Stošić, 2014). Design students' ability to internalize design concepts and grow their own ideas into problem solving skills is germane in the structure of contemporary societies so as to cope with its complex range of design problems.

Studies have viewed design as a highlevel cognitive ability and underscored the link between the cognitive process and the concept of aesthetics in design (Oxman, 1996, Nguyen and Zeng, 2012). This link is considered very important especially in the light of the fact that design thinking is germane to the design process (Dorst, 2011) and the design studio (Oxman, 2004). Furthermore, it is instructive to note that cognitive studies on the design process involving aesthetics have been performed using empirical and experimental methods (Alexiou et al., 2009).

The term "Aesthetics" is used pertaining to beauty in architecture or art (Nia and Suleiman, 2018). Notwithstanding this, Gür 
(2007) observed that the aesthetic meaning is open to debate and depends on the spirit of the era. Much of the scholastic nature of aesthetics, the way it is thought and assimilated in the design studio, however still remain abstruse despite its importance to architecture. Describing its importance, Vitruvius (15 $\mathrm{BC} / 1914$ ) defined good architecture in terms of the three aspects of aesthetics which are: Venustas (beauty), Firmitas (firmness), and Utilitas (utility). Indeed, there is a knowledge gap in the way aesthetic education is experienced and understood and few theories have addressed this. This paper adopts a qualitative grounded theory approach to analyze aesthetic education and the process of attaining it in design studios using a systemic set of procedures which so called systematic review. Clearly stated, the purpose of this article is to unravel the aesthetic pedagogue in architectural design studio through a study on teaching methods in the studios. In doing so, design studio has been stated as the core of architectural education. Accordingly, contributing elements in architectural education have been discussed to develop a comprehensive model based on the design process aiming to modify Bloom Taxonomy in Architecture Design Studios.

\section{MATERIALS AND METHODS 2.1. Architectural Education}

Architecture is an inductive design activity that involves comprehensive processes requiring an analysis phase, programming and designing stage. When these stages are properly aligned, the product is economically feasible and aesthetically pleasing. According to UNESCO/UIA Charter for Architectural education, the point "An ability to create architectural designs that satisfy both aesthetic and technical requirements" is included in the objectives of education. Amongst others, the UNESCO/UIA (2004) Charter specifies that the following is germane to architectural education:

- The consciousness of the relationship between architecture and other creative vocations.

- The mastery of the fine arts as a tool for conveying architectural thoughts thereby enhancing design quality.

Architecture affects the urban aesthetics inasmuch as the buildings which make up the cities are created by architects. Indeed, the Architectural students are the "decision- makers" as far as the aesthetic quality of the environment is concerned (Nia et all., 2017). Thus, in view of the concerns on aesthetics in design studies, the need for a broad based curriculum that embraces the concepts of aesthetic education becomes inevitable. Part of the reasons for this should be to awaken the students to aesthetic problem and curiosity. In this way, their perception of the aesthetic problem will become profound to the end that their ability to apprehend the challenges of the built environment in the design studios is enhanced.

\subsubsection{Design studio as the Core of Architectural Education}

Schön's proposition that "learning is by doing" suggest that the design studio is de facto, the core of architectural education (Schön, 1983; Oh et al., 2013) and a prerequisite for the design curriculum. Although contemporary approach to studio teaching still predicates on the traditional models, progress in a new form of research that targeted reformulating the architectural practice and education in the design studio has supplanted this. As a result, Demirbaş and Demirkan (2007) pointed out that the design studio is fundamental to the design curriculum, arguing that other aspects of the curriculum should be relevant to the design studio.

Furthermore, Rüedi (1996) opined that design is a bridge between realization (social activity) and invention (mental activity). Taking Rüedi views to mean that design is the mediator between both activities, it could also be abstracted that design is an inductive, flexible and undetermined problemsolving process where designers' cognitive abilities are employed. This implies that the design studio facilitate the free exchange of ideas that is both interactional (social) and organizational (students and tutor relationship) in structure. Moreover, the design studio is the first educational environment where first-hand experiences regarding the praxis of the profession can be obtained. Overall, the methods adopted for design education, i.e. teaching and learning helps to balance creativity and critical thinking. The critical process is also facilitated in the design studio. This could owe to student interaction which encourages dialogue and healthy criticism of their designs (Kvan and Jia, 2005). 


\subsubsection{Contributing Elements in Architectural Education}

The educational methods have been seen as a way of organizing the learner's cognitive activity to ensure the acquisition of knowledge and skills of the student in the process of instruction (UNESCO, 1966). It is worthwhile to realize that appropriate method to teach advanced education is flexible and depends on the purpose to be achieved. A variety of teaching techniques such as: seminars, presentations, group discussion, brainstorming and conferences amongst others could be appropriate (Stošić and Stošić, 2013). Each of these has its peculiarity and may be combined to enhance effectiveness. Often times, the combinational effects of visual and auditory method enliven the cognitive and pedagogical process and architectural education. It also enhances students' ability to acquire a richer understanding of the subject by provoking their aesthetic curiosity. From the foregoing, it follows that "Aesthetics" is better understood with interactive education. Open discussion has proved to be most significant as the students participated in this teaching method at all stages of the program (See Figure 1). This provides a platform for intellectual dialogue and brainstorming aside from the nominal lecture periods. Invariably, the platform promotes creativity amongst students.

A further technique employs the use of brainstorming as an intellectual tool to facilitate the development of new aesthetic ideas from listening skills. It has also been used for decision-making, problem-solving as well as creative thinking. Team building is also enhanced by brainstorming (Sajjad, 2011). Apart from this, even the use of music as an instrument for stirring up the senses and understanding the "aesthetic feelings" has been explored. Other methods that have proved effective in awakening the aesthetic curiosity in design studios includes: watching science fiction, reading/listening to famous poets and studying sections from the classics.

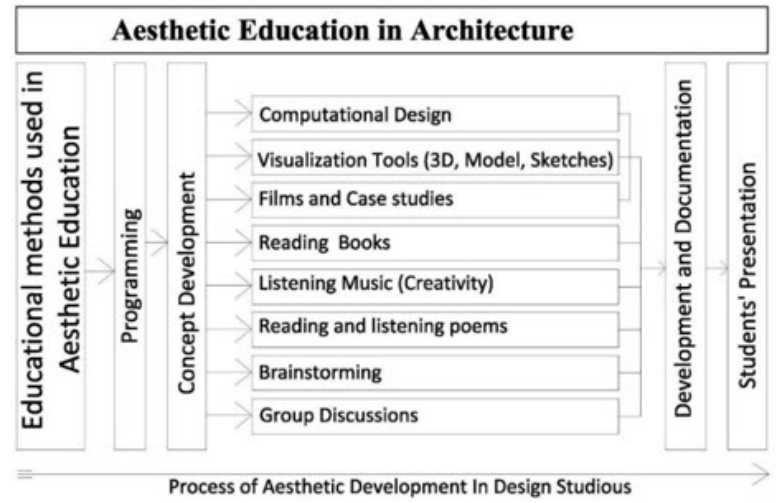

Figure 1. Educational methods used in design studios regarding aesthetics courses.

Eight specific paths to acquiring the aesthetics knowledge in architectural design by means of qualitative data coding have been identified. These are:

c. Design community environment

a. The epochal environment

d. School environment

g. Students' understanding of aesthetics and knowledge of design

h. Reviewers' comments

b. Societal environment

f. Instructors' aesthetic value and aesthetic preference

e. Instructors past educations and experiences

Student's ability to perceive aesthetics under the aesthetic education training scheme will depend on a number of factors which include the tutor's aesthetic preference, experiences, values, judgments and the student's aptitude. This is illustrated in figure 2. Thereafter, the studio influence, the school environment, vision and philosophy are all equally important in providing aesthetic education. Beyond this, the culture of the design community which is impacted by the professional society is very influential. By far, the greatest influence comes from the societal community which of course, epitomizes the norm of the society in its entirety. Thus, Figure 2 illustrates the steps involved in providing aesthetic education in the design studios. 


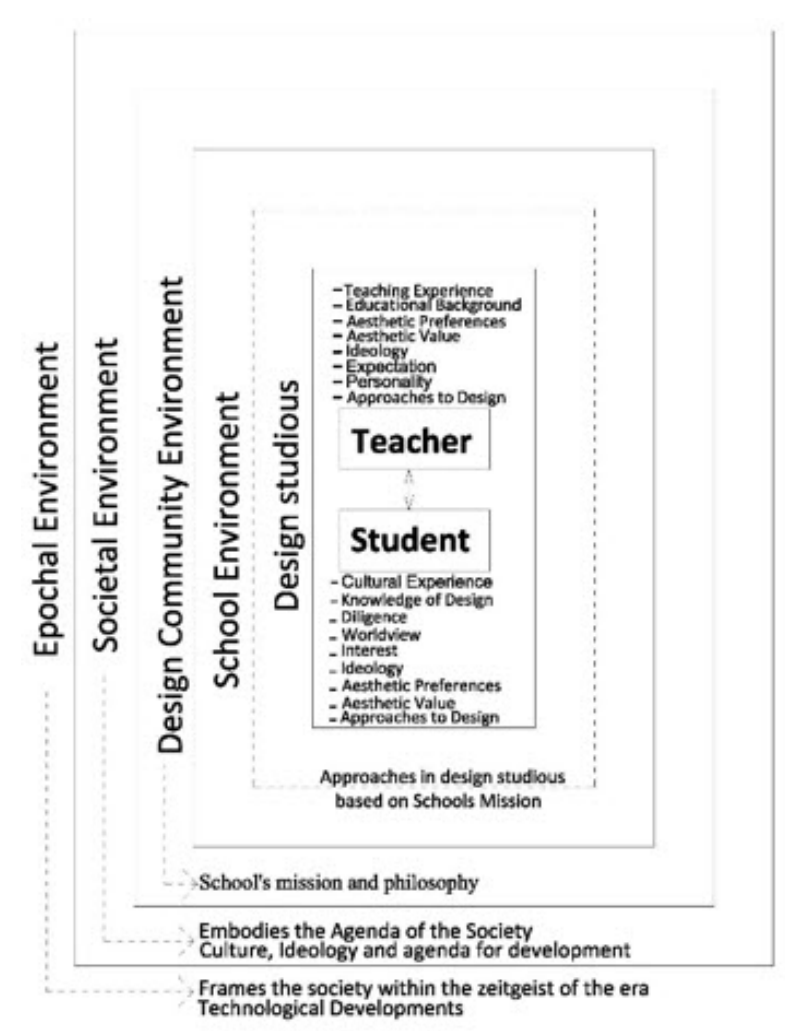

Figure 2. A theoretical model in the process of aesthetic education.

\section{RESULTS}

The design community environment, according to Figure 2, is responsible for the culture of aesthetics as it relates to the profession (this environment infers the makeup of designers and architects). Moreover, the environment may also include the paraphernalia of a board of accreditors who draw up student's educational curriculum and determine the yardstick of their performance, professional organizations that honor outstanding architectural achievements with awards and architectural magazines that promote seminal works.

An objective description of the architectural design process itself may be impossible owing to the subjective approach to design itself; as designers' approaches design differently. Some students for example may be quick to decide on a design direction thereby giving them more room for idea development, while others may be slow at arriving at a direction; making several attempts to test their ideas till they find it convincing.

Other authors have also explored the scholastic attribute of aesthetic education in the design studio. Premised on the character and quality of tutor-student relationship and the type of knowledge transacted, Moore (2001) identified four teaching models: the scientist, the practitioner, the cleric, and the social activist (See Table below).

\begin{tabular}{llll}
\hline $\begin{array}{l}\text { Type of knowledge } \\
\text { transacted in student- } \\
\text { teacher interaction }\end{array}$ & \multicolumn{2}{l}{ Character of student-teacher interaction } \\
\cline { 2 - 4 } & Formal & Facilitator \\
\hline Expert & & The Scientist & The Practitionler \\
\cline { 2 - 4 } & $\begin{array}{l}\text { Epistemological } \\
\text { assumption }\end{array}$ & Knowledge is external & Knowledge is dynamic, negotiable \\
\cline { 2 - 4 } & Teaching style & Expert and formal authority & Instructor and students as co-investigators \\
\cline { 2 - 4 } & Teaching method & $\begin{array}{l}\text { Lecture, teacher-centered } \\
\text { discussion }\end{array}$ & Case studies, problem-based learning \\
\hline Personal & The Cleric & The Social Activist \\
\cline { 2 - 4 } & $\begin{array}{l}\text { Epistemological } \\
\text { assumption }\end{array}$ & $\begin{array}{l}\text { Knowledge cannot be transferred } \\
\text { but is transcendental }\end{array}$ & Knowledge is dynamic, negotiable \\
\cline { 2 - 4 } & Teaching style & Mystical master & Instructor and students as co-investigators \\
\cline { 2 - 4 } & Teaching method & $\begin{array}{l}\text { Self-discovery activities, } \\
\text { coaching, role model }\end{array}$ & Small-group team work, debate \\
\hline
\end{tabular}

Table 1. Pedagogical metaphors and teaching styles (Cho, 2011).

The two models suggested by Moore - Expert or Personal were premised on the knowledge type that exist between the teacher and student. For instance, the abstract quality of aesthetics is immediately visible once it is accepted as a form of knowledge. In this sense, aesthetics is subjective, informal and a reflection of one's personality and values and the aesthetic knowledge passed down to the students from the instructor comes as a result of the instructor's experiences. When viewed from the pedagogical metaphors outlined by 
Moore, the instructors examined in this study appear to differ in style even though their knowledge -type is personal and expertise. They derive their expertise in certain aspects of knowledge such as structure of materials while they share their personal values with respect to aesthetic aspects of buildings. Moreover, we also highlight that the knowledge type delivered by the instructor in the design studio can be analyzed as two different theoretical components which are: normative theory and positive theory. Normative theory is a statement indicating to what extent a thing is acceptable or unacceptable. Positive theory is value-free and the antithesis of the normative theory. Lang (1987) observed that the normative theory addresses the yardstick for the assessment of what is acceptable in the environment as perceived by different designers. In this case, the norms are valued and prioritized. It is worthwhile to note that the nature of normative theory and the aesthetics discuss are mutually inclusive.

Attoe and Mugerauer's (1991) proposed 14 general attributes and examined 20 seminal teachers using in-depth interview method. These characteristics are classified by three main considerations: (1) course format and implementation, (2) personal style, and (3) teacher as self. The findings show that the main information obtained from interview with the studio teachers is more useful in determining their characteristics than from other random sources such as observations or student interviews.

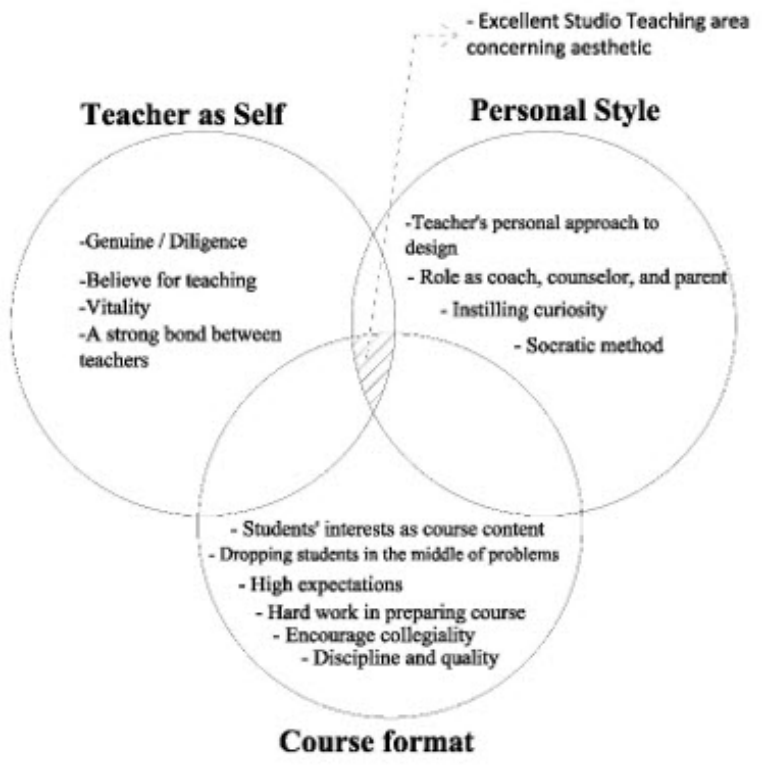

Figure 3. Fourteen Traits of Excellent Studio Teaching.

Thus, by referring to Attoe and Mugerauer's on excellent studio teaching, the link between tutor's emphasis on aesthetics and the adherence of students to their projects can be shown in the diagram below.

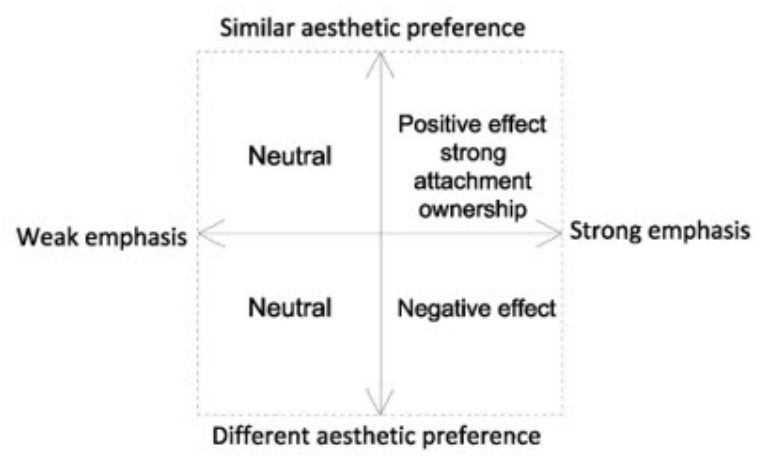

$\mathbf{X}$ axis: instructor's degree of aesthetic emphasis
$\mathbf{Y}$ axis: similarity of aesthetic preferences between instructor and student

Figure 4. Student's affection to his/her project in design studios, consequences from interaction among an instructor's and student's aesthetic preferences and emphasis (Cho, 2011).

Moreover, Figure 4 shows to what extent the instructor emphasizes his aesthetic on the $\mathrm{x}$-axis and the similarity or difference in the aesthetic preference of the student and instructor on the y-axis. It was found that students do not feel the sense of originality in their work when coerced to their instructor's preferred aesthetics. Even when the design is appraised successful, the students still feel that the work is not their own and show a general lack of enthusiasm.

\section{DISCUSSIONS \\ 4.1. Professor and Student Method of Architectural Education}

This method involves reading out. It modifies the old method by introducing cognitive psychology. It has therefore become a relevant subject in textbooks on educational psychology. There are six aspects involved in the professor and student method:

\section{a)- Case studies:}

Here a professor shows the student how to carry out each task; with each task performed with its own uniqueness.

\section{b) - Critiques:}

In this case, the professor supervises student's work by advising appropriately using gestures, feedbacks and guides.

\section{c) - Support (care):}

A professor provides students with initial support according to a specified framework. Thereafter, the students are allowed to work independently to demonstrate the skills acquired during the initial stage. The first 
three stages enrich students' ability to earn recognition and Meta-recognition skills via a systemic process enhanced by experiences and observation.

d) - Scrutiny (self -analyzing): Student manifests unique intellectual characteristics and prowess without recourse to the professor. Thus, in his interaction, the professor provides the student with freedom of self-expression where and when safe.

e)-Expression: In this case, the method is more or less a test. The test allows the student to be examined by the professor and this demand that the student should explain the processes required in carrying out his work.

f)- Revision: Students are encouraged to do a comparative analysis of their work against the backdrop of the professor's work. Here, critical thinking and revision of the student's methods will be involved.

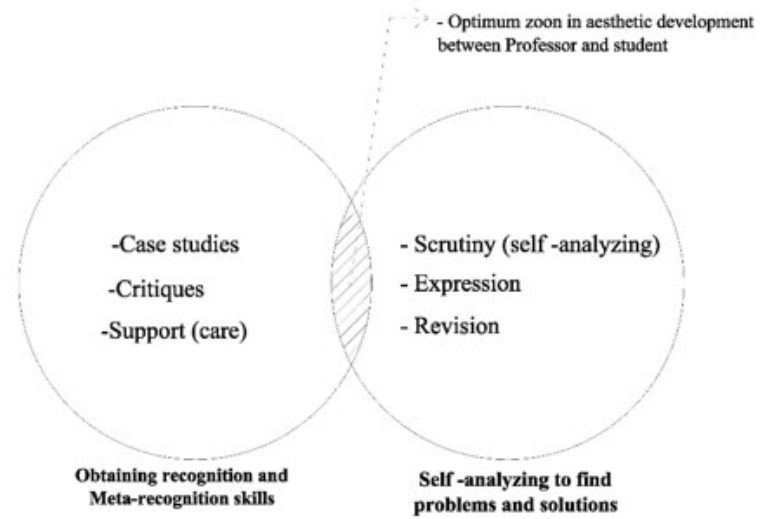

Figure 5. Professor and Student Method in aesthetic development of architectural design studios.

\subsection{Peer Learning Teaching Method of Architectural Education}

Although the Peer-learning teaching method is in its nascent stage, it is both learning and teaching method that takes the form of a lecture/ conference and classmate to classmate teaching. It is therefore a mutual learning process where students play the role of an instructor. Hence, it creates special task for the students - students' as managers and teachers in their own domains. Consequently, by this method the students' level of cognition will be paramount to the learning process. The method is sensitive and valuable to the university education program.

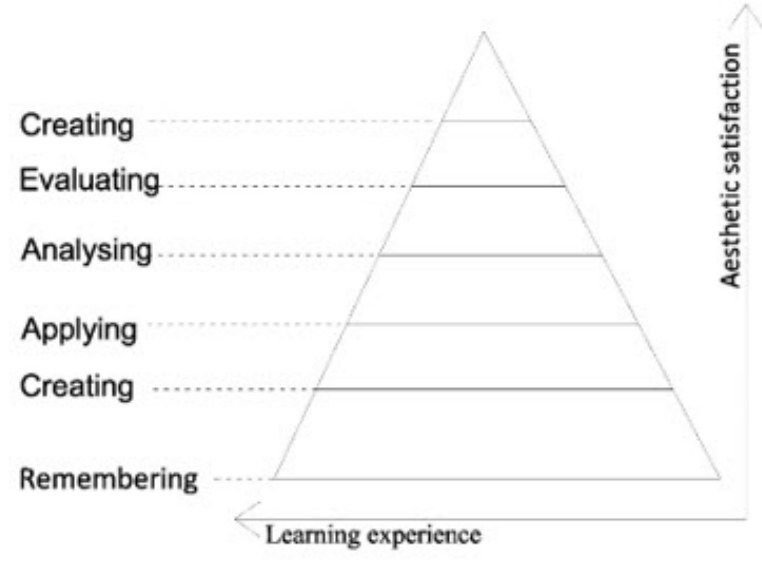

Figure 6. Peer Learning Teaching Method.

Donna Duerk (1993) pointed out that this educational models enhance the design process by stimulating interaction between "Synthesis and Evaluation" in design studios. Recalling that design itself is a systemic process constituted by three basic modules, the impact of each of these designers' concepts and goals are most fundamental to good designs rather than objective analysis.

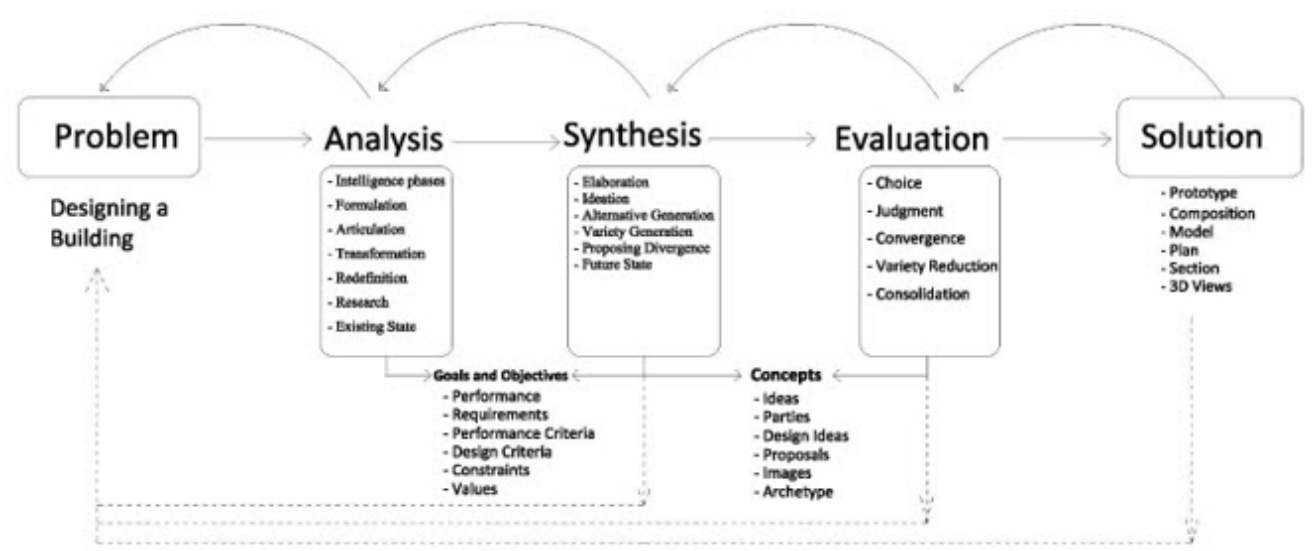

Figure 7. The Design Process: Analysis, Synthesis, and Evaluation. 
Aside to the aforementioned models the Bloom Taxonomy is also examined. It is utilized based on the findings of this research as a checklist for making sure that the Design Studio fulfills its objective of providing design education. Figure 8 illustrates the Bloom
Taxonomy and alongside, expectations of quality levels to be achieved at different stages of the Design Studio. When correctly applied to a design project, the checklist can ensure designers capability for original state of the aesthetic design solutions.

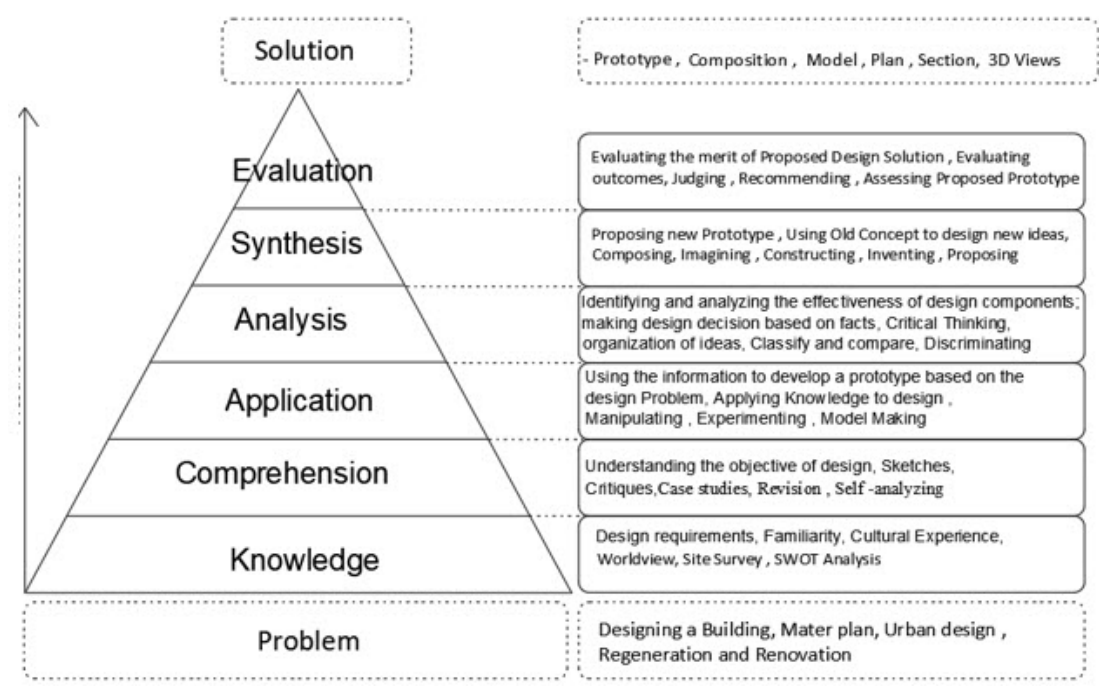

Figure 8. Modified Bloom Taxonomy in Architecture Design Studio

\section{CONCLUSIONS}

Design educators should realize that the purview of architectural education stretches beyond explicit knowledge to discerning beauty in its diversity and in other perspectives. In this way, students of the design studio will better appreciate the plurality of aesthetic beauty.

It is also revealed in this study that educators should be aware that the design studio is an arena for intellectual dialogue, critical thinking and criticism; hence, the possibility of clashes between instructors and students with regard to the aesthetics discuss. The study also stressed that students do not feel the sense of belonging regarding their work when the instructors overstress their aesthetic preferences and force these on the students, in particular, those in advanced-level classes. The study posits that when instructors compel the students to adopt their aesthetic inclinations the results is counter-productive and a teacher -prescriptive approach emerges. Instead, instructors should be suggestive and should and give room for students' aesthetic maturity to evolve naturally.

Furthermore, the study implies that architecture is art inasmuch as it is simply by viewing architecture in this way that it becomes possible to conjoin the principles of aesthetics with architecture. In fact, the collective influence of aesthetics decisions on buildings are germane to the society and to the mental psychologically of individuals that make-up the society. In the overall, this study posits that the concept of Gestalt grouping, symbolic and formal aesthetic should be reinforced in design studio classes to strengthen the idea behind the aesthetics in cities through buildings (Nia and Suleiman, 2018).

Finally, the study also showed that the curriculum structure for the design studio should be all-encompassing so as to guarantee an ideal aesthetic learning process for architecture students. The subject details in the curriculum should be thoughtfully selected to ensure a propitious academic studio environment. Since it is consistent with the aim of the Architecture Design Studio to produce matured students who are creative and show mastery in pragmatic and critical thinking, the application of the Bloom Taxonomy and the stages of students' knowledge attributes as earlier discussed can be utilized as a checklist towards developing aesthetic understanding of students in design studios. The study to assess interrelation of aesthetic Learning Process in Design Studios from fist year to the graduation level has been suggested in this paper for future study. 


\section{ACKNOWLEDGEMENTS}

The authors express their gratitude to Alanya Hamdullah Emin Paşa University and the reviews of the International Journal of Cognitive Research in Science, Engineering and Education (IJCRSEE) for making this research possible.

\section{Conflicts of interests} interest.

The Authors declares no conflict of

\section{REFERENCES}

Alexiou, K., Zamenopoulos. T., Johnson J. H. and Gilbert S. J. (2009). Exploring the neurological basis of design cognition using brain imaging: some preliminary results. Journal of Design Studies. 30(6), pp. 623-647. https://doi. org/10.1016/j.destud.2009.05.002

Attoe, W. and Mugerauer, R. (1991). Excellent Studio Teaching In Architecture. Studies In Higher Education, 16(1), 41-50. https://doi.org/10.1080/0 3075079112331383081

Cho, J. Y. (2011). The Process of Aesthetic Education In Design Studio: A Layperson's Acculturation to the Architecture and Design Community. Journal of Architectural and Planning Research. 30(4), 328-343. Retrieved from: https://www. jstor.org/stable/43031017?seq=1\#metadata info tab contents

Demirbaș, O. O., Demirkan, H. (2007). Learning styles of design students and the relationship of academic performance and gender in design education. Learning and Instruction. 17(3), 345-359. https://doi.org/10.1016/j.learninstruc.2007.02.007

Demirbas, O. O., Demirkan, H. (2003). Focus on architectural design process through learning styles. Design Studies. 24(5), 437-456. https://doi. org/10.1016/S0142-694X(03)00013-9

Demirkan, H., Afacan,Y. (2012). Assessing creativity in design education: analysis of creativity factors in the first-year design studio. Design Studies. 33(3), 262-278. https://doi.org/10.1016/j. destud.2011.11.005

Donna Duerk, P. (1993). Architectural Programming. Information Management for Design. New York: Van Nostrand Reinhold. Retrieved from: https://www.abebooks.com/Architectural-Programming-Information-Management-DesignDuerk/13309222296/bd\%20

Dorst, K. (2011). The Core of 'Design Thinking' and Its Application. Design Studies. 32(6), 521-532. https://doi.org/10.1016/j.destud.2011.07.006

Gür, S. (2007). Modernity Vs. Postmodernityin Architectural Education. Journal of Architectural and Planning Research, 24(2), 91-108. Retrieved from: http://www.jstor.org/stable/43030794

Habibi, A. (2008). Learning through teaching others, Assessment of Education System (peer-to-peer), the articles of the third architecture training conference, University of Tehran, Art Campus, author: Seyed Amir Saeid Mahmoudi. https:// docplayer.net/27104760-Teaching-methods-in- architectural-design-basics.html

Kvan, T., Jia, Y. (2005). Students' learning styles and the correlation with performance in architectural design studio. Design Studies. 26(1), 19-34. https://doi.org/10.1016/j.destud.2004.06.004

Lang, J. (1987). Creating architectural theory. New York: Van Nostrand Reinhold. https:// scholarscompass.vcu.edu/cgi/viewcontent. cgi? article $=1154 \&$ context $=$ jstae

Moore, K. (2001). The scientist, the social activist, the practitioner and the cleric: Pedagogical exploration towards a pedagogy of practice. Journal of Architectural and Planning Research, 18(1), 59-79. Retrieved from: https://www.jstor.org/ stable/43030559?seq=1\#metadata_info_tab_ contents

Nadimi, H. (2010). Teacher-Student Method, Aother Perspective, Journal of Honar-Ha-Ye-Ziba Memary Va Shahrsazi (visual arts, architecture, and urban development), 44(1), 379-387. https://doi. org/10.5902/2179460x20868

Nguyen, T.A., Y. Zeng. (2012). Clustering designers' mental activities based on EEG power. Tools and Methods of Competitive Engineering, Karlsruhe. Edited by I. Horváth, A. Albers, M. Behrendt and Z. Rusák. Proceedings of TMCE 2012, May 7-11, 2012, Karlsruhe, Germany. https://scholar. google.com/scholar?q=Nguyen, $\% 20$ T.A., $\% 20$ Y.\%20Zeng,\%202012.\%20Clustering\%20designers $\% 20$ mental $\% 20$ activities $\% 20$ based $\% 20$ on $\% 20$ EEG\%20power.\%20Tools $\% 20$ and $\% 20$ Methods\%20of\%20Competitive\%20Engineering, $\% 20$ Karlsruhe.

Nia, H. A., \& Suleiman, Y. (2018). Aesthetics of Space Organization: Lessons from Traditional European Cities. Journal of Contemporary Urban Affairs, 2(1), 66-75. https://doi.org/10.25034/ ijcua.2018.3659

Nia, H. A., Alpar, R. \& Rahbaryanyazd, R. (2017). Perception Based Method For Measuring The Aesthetic Quality Of The Urban Environment. Open House international. 42(2). Retrieved From: https://www.researchgate. net/profile/Hourakhsh Ahmad Nia/publication/312191981 Perception Based Method for_Measuring_the_Aesthetic_Quality_of the Urban Environment The Case of Famagusta/ links $/ \overline{5}$ ca865244585 $\overline{1} 57 \mathrm{~b} \overline{\mathrm{d}} 3254 \overline{6} 9 \overline{\mathrm{f}} /$ PerceptionBased-Method-for-Measuring-the-AestheticQuality-of-the-Urban-Environment-The-Caseof-Famagusta.pdf

Nia, H., \& Suleiman, Y. (2017). Identity in Changing Context: Factors of losing Identity in new developed part of the city of Famagusta, North Cyprus. Journal of Contemporary Urban Affairs, 1(2), 11-20. https://doi.org/10.25034/ ijcua.2018.3661

Oh, Y., Ishizaki, S., Gross, M.D. \& Do, E. Y. L. (2013). A theoretical framework of design critiquing in architecture studios. Design Studies. 34(3), 302-325. https://doi.org/10.1016/j. destud.2012.08.004

Oxman, R. (1996). Cognition and design. Journal of Design Studies. 17(4), Pp 337-340. https://doi. org/10.1016/S0142-694X(96)90000-9

Oxman, R. (2004). Think-maps: teaching design thinking in design education. Journal of Design Studies. 25(1), pp 63-91. https://doi.org/10.1016/ S0142-694X(03)00033-4

Rüedi, K. (1996). Architectural Education and the Cul- 
ture of Simulation: history against the Grain. In:Hardy, A.,Teymur, N. (Eds.), Architectural Education and the Culture of Simulation: history against the Grain, pp. 109-125. Retrieved from: http://refhub.elsevier.com/S20952635(15)00039-4/sbref53

Sajjad, S. (2011). Effective Teaching Methods At Higher Education. Proceedings of The first international conference of the WFATE. Retrieved from: http://class.web.nthu.edu.tw/ezfiles/669/1669/ img/1381/1.Effectiveteachingmethodsathighereducationlevel.pdf

Schön, D. A. (1983). The Reflective Practitioner: How Professionals Think in Action, Basic Books: United States. Retrieved from: https://www. sopper.dk/speciale/arkiv/book49.pdf

Schön, D. A. (1985). The design studio: An exploration of its traditions and potentials. London: RIBA Publications for RIBA Building Industry Trust. Retrieved from: https://trove.nla.gov.au/ version $/ 45633888$

Stošić, L., \& Stošić, I. (2013). Diffusion of Innovation in Modern School. International Journal of Cognitive Research in Science, Engineering and Education (IJCRSEE), 1(1), 5-13. Retrieved from https://www.ijcrsee.com/index.php/ ijcrsee/article/view/219

Stošić, L., \& Stošić, I. (2014). Impact of Computers on the Creativity of Children. International Journal of Cognitive Research in Science, Engineering and Education (IJCRSEE), 2(2), 29-34. Retrieved from https://www.ijcrsee.com/index. $\mathrm{php} / \mathrm{ijcrsee} / \mathrm{article} / \mathrm{view} / 131$

UNESCO/UIA, (2004). UIA Work Programme 'Education' UIA/UNESCO Charter for Architectural Education. UIA General Assembly. Retrieved from: http://www.unesco.org/most/ uiachart.htm

UNESCO/UIA. (1966). UIA Work Programme 'Education', UIA/UNESCO Charter For Architectural Education. http://www.unesco. org/most/uiachart.htm

Vyas, D., Van der Veer, G \& Nijholt, A. (2013). Creative practices in the design studio culture: collaboration and communication. Cognition, Technology \& Work. 15(4), 415-443. https://doi. org/10.1007/s10111-012-0232-9

Yang, M. C. (2010). Consensus and single leader decision-makingin teams using structured design methods. Design Studies. 31(4), 345-362. https://doi.org/10.1016/j.destud.2010.03.002 